\title{
EPILEPTIC RESPONSE TO PERIPHERAL INJURY
}

\author{
BY \\ GERALD PARSONS-SMITH \\ Neurological Department, St. George's Hospital, London
}

(REeEIVED MAY 15, 1948)

From a study of the literature it is apparent that in certain cases of reflex epilepsy there is an association between the epileptic response and peripheral injury. About one hundred years ago there was a woman who suffered from generalized epileptic convulsions. Her left arm had been amputated at about the middle of the humerus, and she later complained of localized convulsions in the stump. Hancock (1852) removed a large neuroma from the stump with only temporary alleviation, and he later had to remove the limb at the shoulder joint, but two months later the shoulder muscles around the scar became convulsed.

The probing of an infected sinus of a femur (Parker, 1887), or the stretching of a traumatized sciatic nerve (Hadden, 1887), were followed by seizures. Critchley (1933) described a patient who had a typical epileptic attack whilst a dressing was being applied by her doctor to her burnt arm. She had never before had a fit, but her child was an idiopathic epileptic. Mitchell and Spiller (1904) described two such cases. The first, a soldier in the American Civil War, had been wounded in the sciatic nerve, and the second, another soldier, had had his arm amputated. Both of these patients developed continuous movements in the stump of the affected limb which, when restrained, were followed by more generalized convulsions.

Holmes, in his Savill Memorial Oration for 1927, related that whilst he had been studying the disturbances of sensation produced by cortical lesions he had found, during prolonged examination of tactile and other forms of cutaneous sensibility over one hand, that Jacksonian spasms occasionally began in this part in patients with cortical lesions who were not subject to frequent attacks. Indeed some patients were reluctant to submit to examination when they realized the connexion. $\mathrm{He}$ considered that the most effective stimulus was light touch with a camel-hair brush.
Feiling, in his Lettsomian Lectures for 1942, also recorded the connexion between epileptic convulsions and peripheral nerve injury. He had found that in a few cases of this kind the attacks began by abnormal sensations arising in the injured area, which often spread to involve the whole of the same side of the body and which in some instances culminated in a generalized fit. He had observed a soldier who had been wounded in the right elbow in the 1914 war and whose arm had been amputated. About twelve years later the sensory attacks started. These consisted of slight twitchings which arose in the stump and spread after a while to the right side of the face, trunk, and leg. Two or three years later the convulsions spread to the opposite side of the body, and when this occurred consciousness was lost. Handling of the amputation stump did not act as an excitant to the attack.

Apart from Holmes's cases (1927), where a cortical lesion had caused the disturbed peripheral response to a specific and effective stimulus, little is known of the nature of the abnormal physiology of reflex epilepsy. Because of this it would seem to be worth while to record any case in which something is known about the relationship of an abnormal peripheral mechanism to epileptic fits. The following case is therefore described in some detail as it presents evidence of abnormal cortical function together with peripheral nerve injury, both of which abnormalities were acquired before the occurrence of the patient's first epileptic.fit, in which the nature of the sensory precipitant and its site of action were constant.

\section{Case Report}

H.M. was an unmarried van driver aged 41 years. He came from healthy stock, and no history of fits or migraine could be elicited. He had had no serious illness until he contracted malaria in 1930, whilst abroad in the Army, and four years later, whilst still in India, he had been treated for tape-worm infestation. He was 
again treated for a recurrence of this complaint in 1940 . He had "spinal meningitis" in 1940, which was cured in seven weeks. Little is known of the exact nature of this illness, but there have been no sequelæ and he remained well for the next six years. On Jan. 27, 1947, he accidentally crushed his left hand beneath a twohundredweight cable drum. This produced a cut on the dorsum of the left hand, about an inch long, at a level of the bases of the second and third metacarpal bones, and this was deep enough for him to be able to see his tendons. He noticed shortly afterwards that the whole of the thumb, the dorsum of the index finger, and outer half of the middle finger seemed numb ; clinical examination later showed that this numbness was due to local damage to the terminal cutaneous branch of the radial nerve.

It was about twenty-four hours later that, while sorting some papers, he noticed that these seemed to tickle his left thumb and index finger in a curious way, which description he could not amplify except that it felt quite pleasant to him. This was followed suddenly by stiffening of the thumb and first two fingers. The thumb was adducted into the palm, then the fingers flexed at the metacarpo-phalangeal joints. Within a second or two of this happening the whole arm began a series of jerking movements, the elbow became flexed and the arm rose to a position of abduction at the shoulder until it formed an angle of 90 degrees with the trunk. The fit lasted for about half a minute, but recurred two or three times a day for the next week, being provoked by only mild and light stimuli. He found that knocking or hurting his hand did not act as a trigger. Owing to the position of abduction which the arm assumed, he became very self conscious, and tried by gripping his knee with his hand to restrain the limb. He found, when he did this, that the embarrassing abduction could be avoided and also that the limb would "cool down" quicker, and that the episode would be much milder.

About ten days after the injury he was sorting some requisition slips in his van when he suddenly appreciated that the curious tickling sensation produced by the papers on his left hand was spreading up his left arm. He gripped his knee tightly, but the feeling continued to spread, his jaw became clenched and he felt that his face was twisted. This was followed by a steam-enginelike noise in his head and he lost consciousness. He recovered in about twenty minutes, felt confused, and found that he had bitten his tongue.

He was examined about three weeks later at the National Hospital for Nervous Diseases, Queen Square, London, and no abnormal physical signs were found except for an area of blunting to pin prick over the dorsum of the left thumb and the index and outer half of the middle fingers corresponding with part of the area supplied by the terminal part of the superficial branch of the radial nerve. On April 28, 1947, he was admitted to the hospital for investigation under the care of Dr. Denis Williams. Radiograph of the limb muscles demonstrated the presence of calcified cysts. Although no abnormal calcification could be seen within the skull, the cerebrospinal fluid was abnormal. It was clear, contained 46 cells per c.mm., 18 polymorphs, and 28 lymphocytes, and $50 \mathrm{mg}$. of protein per $100 \mathrm{c.cm}$. The Wassermann reaction was negative in the blood and cerebrospinal fluid. The electro-encephalogram showed no physiological dominant frequency, and there was persistent low voltage fast activity in all leads with no focal origin. There was no sign of any local disorder and the curves were symmetrical. A diagnosis of cerebral cysticercosis was made and he was discharged from hospital with a prescription of Tab. phenobarbitone, gr. $\frac{1}{2}$ three times a day, which dosage was sufficient to prevent any further seizures during the next eight months.

The next examination was made at St. George's Hospital, London, on Oct. 24, nine months after his injury, and except for some impairment of appreciation of pin prick over the back of the outer three digits, which extended along the outer side of the index finger, there were no other abnormal physical signs. He had not taken any sedative for four days before the appointment. Electro-encephalographic investigations were then carried out. With the patient lying at rest, records were taken with a Grass 6 channel apparatus. The alpha rhythm was of low voltage, very unstable, and of a frequency of 10 to $12 \mathrm{c} / \mathrm{sec}$. Continuous low voltage fast activity at 18 to $22 \mathrm{c} / \mathrm{sec}$. was present in all leads, but was best seen in both parietal regions. The records were quite symmetrical, there was no evidence of any focal abnormality. There was no abnormal response to overbreathing. The electro-encephalogram was then recorded while various surprise stimuli were applied to the area of impaired sensation on the patient's left hand and also, so as to serve as a control, at a different time to the corresponding area on the right hand. The patient was not informed of the nature of the stimuli nor when they would be applied. The period of stimulation lasted for about one minute in each case. First the effect of tickling lightly with cotton wool was tried. $\mathrm{He}$ remarked afterwards that this felt very different on the two hands, that on the epileptogenic zone being "pleasant," whilst that on the control area was "just ordinary." Next a slightly heavier touch with cotton wool was applied, then slowly repeated rhythmic pin pricks, showers of rapid pin pricks, and sudden very loud noises. Finally he was given some slips of paper which he fingered and rustled in both hands. Careful study of the electro-encephalographic records showed that not one of these various stimuli produced the slightest change in the curves suggestive of epileptic discharge, and except for a few artifacts the records were unchanged.

He remained symptom-free, continuing to take Tab: phenobarbitone gr. $\frac{1}{2}$ three times a day, until Chrisțmas morning, 1947, when, as he was screwing up some newspaper with which to light a fire; he produced the aura in the left thumb and first finger. He swore loudly, gripped the fender as hard as he could, and thus aborted the attack. He had another minor focal seizure that afternoon, but he does not remember what the trigger was on that occasion. That night he played cards with three friends. Early in the game he was dealing the cards with his right hand and at the same time was. pushing the cards forward from the pack, which he held 
in his left hand, on to the lateral side of his index finger. This produced the usual aura which on this occasion proceeded to a major fit. Since then the dosage of phenobarbitone has been increased to gr. 1 three times a day and there has been no recurrence of fits. About the beginning of February, 1948, he observed some tapeworm segments in his stools. He was therefore treated with filix mas, but a careful search of the stools did not reveal the head of the tænia solium. Two weeks later he was treated with carbon tetrachloride and oil of chenopodium, again without success.

A further neurological examination was made on March 31, 1948. No abnormal physical signs were found, and sensation in the left hand was apparently normal. Another electro-encephalographic examination was carried out, and the experiments of the previous examination were repeated. He was also' lightly stroked with a camel-hair brush for fifteen minutes on the left index finger, during which period he overbreathed for six minutes, but as before there was no change in the character of the electro-encephalographic records.

\section{Discussion}

After careful analysis of cases of this type, and' study of the experimental work which has been performed, it is only possible to speculate on the mechanism of the production of this kind of epileptic response. It is possible that in those cases associated with peripheral injury there may be some abnormality in the reflex arc on the afferent side between the periphery and the cortex. Holmes (1927). refers to Sauerbruch, who had passively moved a monkey's paw for a long period. After such exercise, injection of cocaine in a previously ineffective dose produced a spasm of the limb. Clementi (1931) applied strychnine near the uncinate gyrus of a dog, after which fits could be provoked by olfactory stimulation with pungent substances. Muskens (1928) quotes Amantea, who applied strychnine to the motor centre of an extremity, after which painful stimulation of the limb resulted in a fit.

Denny-Brown and Robertson (1934) in a very intensive study of local epileptic convulsions which they carried out before the electro-encephalogram was used in epilepsy, put forward the hypothesis that the fundamental epileptic process is continuous and widespread, and in its lesser intensities productive of outward effect only by coalition with other intense nervous processes, and that the added stimulus is related solely to its power to cause a sudden increase in excitability in the patient concerned. The electro-encephalogram does in fact show that external stimuli can alter the rate and rhythm of the waves. For instance whilst an electro-encephalogram is being recorded the effect of the opening of the eyes is frequently observed. As a rule the alpha rhythm is blocked when the eyes are open, but when the eyes are shut the alpha rhythm resumes immediately. It is a not infrequent finding in patients with idiopathic epilepsy that a burst of epileptic activity, generally in the form of a spike and wave, occurs as soon as the eyes have been shut to command. In a series of abnormal epileptic electro-encephalographs recorded at St. George's Hospital 9 per cent. exhibited this phenomenon. Goodkind (1936) and Robinson (1939) have both reported sensory precipitation of this kind. Shaw and Hill (1947) investigated a case of musicogenic epilepsy and produced evidence on the electroencephalogram to show that there was a constant pattern for the development of the fit. No change of rhythm was seen while music was played before the fit began, and the cortical discharge did not begin until six or seven seconds after the clinical onset. Dawson (1947) described a subject in whom sensory stimulation, in the form of stretching a muscle or electrical stimulation of a peripheral nerve, provoked myoclonic seizures. He showed conclusively that a peripheral stimulus caused an afferent volley which resulted in an electrical change of potential over the contralateral scalp. Thus. stimulation of a leg was followed by a response near the mid-line, or 6 to $8 \mathrm{~cm}$. lateral to it, when the arm was stimulated. He concluded that these responses. to stimulation are cerebral in origin.

In the case here described the actual nerve injury did not serve as a noxious stimulus to the reflex, nor did the ordinary sensations of pain, pressure, touch, etc., act as excitants, but in his case a light tickling touch applied to the area supplied by the injured nerve resulted in about twenty focal fits, two of which progressed to major attacks with convulsions. It seems that the stimulus of light touch was altered as the result of the peripheral nerve injury and that. it served to detonate a focal cortical outburst. It is remarkable that the epileptic fits should have started so constantly in that exact part of the body which had been injured, and that it always required the same type of stimulus to release the trigger. Although the incidence of the fits was most frequent in the first few days after the injury, and very infrequent since, he has for the greater period of the time been receiving a regular dosage of $T a b$. phenobarbitone, so the healing of the peripheral nerve injury is not necessarily the only reason for the improvement.

It is of interest to note that, in this case, the stimulus which acted as a trigger was of a very similar type to that which was found by Holmes to provoke the epileptic responses in his cases. He had also remarked upon the fact that with stimulation the clonic movements start almost invariably in the part that was being tested. Holmes. 
considered that there was evidence that stimulation of a limb, which is subject to motor or sensory epilepsy, or of a sense organ to which analogous phenomena are referred, may excite epileptic symptoms if the corresponding part of the cortex is in an unstable state. Dawson (1947) has, by electrical means, been able to confirm this concept which Holmes had reached by clinical observation.

\section{Summary}

A case of symptomatic epilepsy is described where the fits were precipitated by the passage of a specific sensory stimulus through an injured peripheral nerve.

I am very grateful to Dr. Denis Williams for permission to publish this case, and for his guidance in the preparation of this report.

\section{REFERENCES}

Clementi, A. (1931). Arch. Fisiol., 30, 1.

Critchley, M. (1933). Ann. Rep. Lond. Co. Council, vol. 4, part 3, p. 133. (1935). Schweiz. Arch. Neurol. Psychiat., 35, 256.

Dawson, G. D. (1947). J. Neurol. Neurosurg. Psychiat., $10,141$.

Denny-Brown, D., and Robertson, E. G. (1934). Neurol. Psychopath., 15, 97.

Feiling, A. (1942). Trans. med. Soc. Lond., 63, 178.

Goodkind, R. (1936). Arch. Neurol. Psychiat., Chicago, 35,868 .

Hadden, W. B. (1887). Brit. med. J., 1, 510.

Hancock, Mr. (1852). Lancet, 1, 281.

Holmes, G. (1927). Ibid., 1, 957.

Mitchell, S. W., and Spiller, W. G. (1904). Trans. Assoc. Amer. Phys., 19, 433.

Muskens, L. J. J. (1928). " Epilepsy." London.

Parker, R. W. (1887). Proc. med. Soc. Lond., 10, 85.

Robinson, L. J. (1939). J. Nerv. ment. Dis., 90, 333.

Shaw, D., and Hill, D. (1947). J. Neurol. Neurosurg. - Psychi_t., 10, 107. 